\title{
Resection of middle petroclival meningioma via combined anterior transpetrosal and retrosigmoid approaches at two separate stages: 3D operative video
}

\author{
Ihsan Dogan, MD, ${ }^{1}$ Pinar Eser Ocak, MD,1 G. Mark Pyle, MD, ${ }^{2}$ and Mustafa K. Başkaya, MD1 \\ Departments of ${ }^{1}$ Neurological Surgery and ${ }^{2}$ Otolaryngology, University of Wisconsin School of Medicine and Public Health, \\ Madison, Wisconsin \\ Surgical access to the petroclival region poses a challenge to neurosurgeons. A wide range of approaches has been \\ demonstrated in the past. In this video, the authors present a 69-year-old male patient who presented with 3-month \\ history of worsening left-sided numbness. The tumor was totally removed in 2 sessions via anterior transpetrosal and \\ retrosigmoid approaches, respectively. The authors demonstrate 2 separate skull base approaches to resect a petro- \\ clival meningioma and discuss pitfalls and problems of management for challenging meningiomas. The authors suggest \\ that surgical approaches to petroclival meningiomas should be selected based on an individual case. A skull base team \\ should be versatile in performing all these approaches.
}

The video can be found here: https://youtu.be/BCVrn3TeNvE.

KEYWORDS skull base; petroclival meningioma; anterior transpetrosal; retrosigmoid

SUBMITTED June 4, 2017. ACCEPTED June 28, 2017.

INCLUDE WHEN CITING Published online October 1, 2017; DOI: http://thejns.org/doi/abs/10.3171/2017.10.FocusVid.17379.

CORRESPONDENCE Mustafa K. Başkaya, Department of Neurological Surgery, University of Wisconsin Medical School, K4/834 CSC, 600 Highland Ave., Madison, WI 53792. email: m.baskaya@neurosurgery.wisc.edu. 